\title{
Upper gastrointestinal motility and symptoms in individuals with diabetes, prediabetes and normal glucose tolerance
}

\author{
Georgios C. Boronikolos • Björn A. Menge • \\ Nina Schenker • Thomas G. K. Breuer • Jan-Michel Otte • \\ Sascha Heckermann • Freimut Schliess • Juris J. Meier
}

Received: 29 August 2014 / Accepted: 2 February 2015 /Published online: 1 March 2015

(C) Springer-Verlag Berlin Heidelberg 2015

\begin{abstract}
Aims/hypothesis Type 2 diabetes has been associated with upper gastrointestinal motility dysfunction, but the relationship with diabetes duration and glucose control is less well understood. Gastric emptying, oesophageal motility and gastrointestinal symptoms were examined in volunteers with diabetes, prediabetes (impaired fasting glucose [IFG] or impaired glucose tolerance [IGT]) and normal glucose tolerance (NGT).

Methods The study included 41 patients with type 2 diabetes, 17 individuals with IFG/IGT and 31 individuals with NGT. A gastric emptying breath test and high-resolution oesophageal manometry were performed. Gastrointestinal symptoms were assessed using questionnaires.

Results Gastric emptying was delayed in individuals with IFG/IGT $(p<0.05)$ but was normal in the diabetic group. Amongst the diabetic patients, gastric emptying rate was fastest in those with longer diabetes duration and the highest $\mathrm{HbA}_{1 \mathrm{c}}$ levels $(p<0.001)$. Oesophageal motility variables were similar between the groups. However, the lower oesophagus resting pressure was reduced in patients with longer diabetes duration $(p=0.01)$. Abdominal pain/discomfort was
\end{abstract}

Electronic supplementary material The online version of this article (doi:10.1007/s00125-015-3538-3) contains peer-reviewed but unedited supplementary material, which is available to authorised users.

G. C. Boronikolos $\cdot$ N. Schenker · J. J. Meier $(\bowtie)$

Diabetes Division, Department of Medicine I, St Josef Hospital, Ruhr University Bochum, Gudrunstr. 56, 44791 Bochum, Germany

e-mail: juris.meier@rub.de

B. A. Menge $\cdot$ T. G. K. Breuer $\cdot$ J.-M. Otte

Department of Medicine I, St Josef Hospital, Ruhr University

Bochum, Bochum, Germany

S. Heckermann • F. Schliess

Profil Institute for Metabolic Research, Neuss, Germany more frequent amongst patients with diabetes $(p=0.04)$ but was unrelated to gastric emptying. Significant associations between various oesophageal motility variables and gastrointestinal symptoms were observed.

Conclusions/interpretation Gastric emptying and oesophageal motility are not generally altered in patients with type 2 diabetes. In more advanced disease stages, however, gastric emptying and oesophageal motility may be disturbed, probably as a consequence of autonomic neuropathy. Delayed gastric emptying in IFG/IGT individuals might be secondary to acute hyperglycaemia. Determination of gastric emptying and oesophageal manometry should be considered for the diagnostic workup of patients with diabetes and gastrointestinal symptoms.

Keywords Abdominal symptoms - Autonomic neuropathy · Gastric emptying - Oesophageal manometry · Postprandial hyperglycaemia

$\begin{array}{ll}\text { Abbreviations } \\ \text { DBSQ } & \text { Diabetes Bowel Symptom Questionnaire } \\ \text { DPP-4 } & \text { Dipeptidyl-peptidase 4 } \\ \text { GCSI } & \text { Gastroparesis Cardinal Symptom Index } \\ \text { GLP-1 } & \text { Glucagon-like peptide-1 } \\ \text { IFG } & \text { Impaired fasting glucose } \\ \text { IGT } & \text { Impaired glucose tolerance } \\ \text { LES } & \text { Lower oesophageal sphincter } \\ \text { NGT } & \text { Normal glucose tolerance } \\ t_{\text {LAG }} & \text { Lag time }\end{array}$

\section{Introduction}

Glucose homeostasis and upper gastrointestinal functions are tightly interrelated [1-3]. It is well known that gastric 
emptying has a major impact on postprandial glucose regulation [4]. Decelerating the velocity of gastric emptying or intestinal glucose absorption has been established as a glucoselowering principle in the treatment of type 1 and type 2 diabetes [5-8]; accelerating gastric emptying can increase postprandial glucose excursions [9]. Furthermore, various peptide hormones from the gastrointestinal tract, especially the incretins glucose-dependent insulinotropic polypeptide and glucagon-like peptide-1 (GLP-1) have important glucoregulatory actions [10-13].

Glucose metabolism can influence upper gastrointestinal motility. Various studies have demonstrated that acute hyperglycaemia markedly delays the rate of gastric emptying, slowing down the entry of nutrients into the circulation [14, 15]. Under conditions of hypoglycaemia, gastric emptying is typically accelerated, which facilitates the delivery of glucose into the duodenum [16].

While the acute effects of different glucose concentrations on gastric emptying are generally well accepted, controversial findings have been reported in patients with type 2 diabetes. Accelerated, delayed and normal gastric emptying rates have all been found in different studies in patients with type 2 diabetes [2, 17-23]. It has also been reported that upper gastrointestinal symptoms are more prevalent in patients with type 2 diabetes than in non-diabetic individuals [2].

Oesophageal motility has been less well studied in patients with type 2 diabetes. The available studies have demonstrated normal oesophageal motility, delayed oesophageal transit times and reduced pressure of the lower oesophageal sphincter (LES) [22, 24-26]. However, most of these studies have been performed using conventional manometry catheters, which do not allow for continuous pressure monitoring throughout the oesophagus.

Although the use of different methods (scintigraphy, ultrasound, MRI, dye dilution techniques, breath tests for gastric emptying, conventional multichannel manometry or radiographic examinations for oesophageal motility) may explain some of the discrepancies between these studies, it is likely that different patient characteristics also have a major impact on the respective results. In this regard the extent of autonomic neuropathy, the quality of glucose control and the duration of diabetes are clearly important $[2,23]$.

Finally, the potential alterations in oesophageal motility and gastric emptying in prediabetic individuals (those with impaired fasting glucose [IFG] or impaired glucose tolerance [IGT]) are largely unknown. The present study therefore applied high-resolution oesophageal manometry and a validated gastric emptying breath test to examine the prevalence and extent of upper gastrointestinal disorders in individuals with diabetes, IFG/IGT and normal glucose tolerance (NGT). The findings were analysed in relation to subjectively reported gastrointestinal symptoms, patient characteristics and postchallenge glucose control.

\section{Methods}

Study design

A prospective study was designed to examine various autonomic disorders in relation to oral glucose tolerance. This manuscript reports the findings of the examinations of upper gastrointestinal functions and symptoms. Participants with and without known diabetes were recruited from local advertisements, as well as through patient database screening, and asked to participate in a series of gastrointestinal, cardiological and neurological tests. In patients without previously known type 2 diabetes, an OGTT was performed to assess glucose tolerance status. Thereafter, volunteers were categorised according to American Diabetes Association diagnostic criteria as having NGT, prediabetes (IFG or IGT) or diabetes according to their oral glucose tolerance and patient history [27]. The study protocol was approved by the local ethics committee of Ruhr University Bochum (26 August 2010), and all participants gave their written informed consent.

\section{Study participants}

A total of 89 individuals (45 men and 44 women) of European descent participated in the study. Amongst those, 41 had type 2 diabetes, 17 had prediabetes (11 IFG and six IGT) and 31 had NGT. Participants' characteristics are reported in Table 1. In four of the 41 patients with type 2 diabetes, the diagnosis was newly made on occasion of the OGTT. Twenty-six patients were treated with oral glucose-lowering drugs only (metformin in 21 cases, sulfonylureas in nine cases, dipeptidyl-peptidase 4 (DPP-4) inhibitors in nine cases, meglitinides in three cases), four patients were on insulin only, and seven patients were treated with a combination of insulin and oral glucose-lowering drugs (metformin in six cases, sulfonylurea in one case, DPP-4 inhibitors in two cases). The mean diabetes duration was $10.1 \pm 1.3$ years. None of the participants was taking any medication known to affect gastric emptying. To minimise confounding effects of various comorbidities, specific exclusion criteria were applied for each test and are detailed in the electronic supplementary material (ESM) Methods.

\section{Study procedures}

Screening visit All participants underwent a general clinical examination and the following variables were assessed: age, height, weight, waist and hip circumference. Venous blood samples were taken for measurement of standard haematological and clinical chemistry variables. Vibration sense was determined at the malleolus medialis using a Rydel-Seiffer tuning fork. In participants without previously known diabetes, an OGTT was performed over $120 \mathrm{~min}$. If participants met 
Table 1 Characteristics of the study population
Data are mean \pm SEM

$p$ values were calculated using one-way ANOVA

*Significant differences vs controls (Student's $t$ test)

ALT, alanine transaminase; AST, aspartate transaminase; GGT, $\gamma$-glutamyltranspeptidase; SGOT, serum glutamic-oxaloacetic transaminase; SGPT, serum glutamic-pyruvic transaminase

\begin{tabular}{lllll}
\hline Variable & Diabetes & IFG/IGT & NGT & $p$ value \\
\hline Age $($ years $)$ & $65.7 \pm 1.1$ & $69.1 \pm 1.4^{*}$ & $63.6 \pm 1.7$ & 0.07 \\
BMI $\left(\mathrm{kg} / \mathrm{m}^{2}\right)$ & $31.9 \pm 0.7^{*}$ & $27.9 \pm 1.3$ & $27.4 \pm 0.8$ & 0.0003 \\
Haemoglobin $(\mathrm{g} / \mathrm{l})$ & $146.4 \pm 1.8^{*}$ & $141.1 \pm 3.8$ & $140.8 \pm 2.1$ & 0.13 \\
AST $(\mathrm{SGOT})(\mu \mathrm{kat} / \mathrm{l})$ & $0.5 \pm 0$ & $0.5 \pm 0$ & $0.4 \pm 0$ & 0.31 \\
ALT $(\mathrm{SGPT})(\mu \mathrm{kat} / \mathrm{l})$ & $0.6 \pm 0.1^{*}$ & $0.5 \pm 0$ & $0.4 \pm 0$ & 0.02 \\
GGT $(\mu \mathrm{kat} / \mathrm{l})$ & $0.8 \pm 0.1$ & $0.4 \pm 0.1$ & $0.5 \pm 0.1$ & 0.03 \\
Cholinesterase $(\mathrm{kU} / \mathrm{l})$ & $9.4 \pm 0.2^{*}$ & $8.7 \pm 0.3$ & $8.4 \pm 0.4$ & 0.04 \\
Alkaline phosphatase $(\mu \mathrm{kat} / \mathrm{l})$ & $1.2 \pm 0.1$ & $1.1 \pm 0.1$ & $1.1 \pm 0$ & 0.68 \\
Urea $(\mathrm{mmol} / \mathrm{l})$ & $13.4 \pm 0.5$ & $12.8 \pm 1$ & $12 \pm 0.7$ & 0.51 \\
Creatinine $(\mu \mathrm{mol} / \mathrm{l})$ & $85.7 \pm 2.6$ & $84 \pm 4$ & $80 \pm 2.8$ & 0.34 \\
Total cholesterol $(\mathrm{mmol} / \mathrm{l})$ & $5.1 \pm 0.2^{*}$ & $5.6 \pm 0.2$ & $5.8 \pm 0.2$ & 0.02 \\
Triacylglycerols $(\mathrm{mmol} / \mathrm{l})$ & $1.8 \pm 0.2^{*}$ & $1.5 \pm 0.2$ & $1.3 \pm 0.1$ & 0.06 \\
HDL-cholesterol $(\mathrm{mmol} / \mathrm{l})$ & $1.3 \pm 0.1^{*}$ & $1.8 \pm 0.1$ & $1.8 \pm 0.1$ & 0.0001 \\
LDL-cholesterol $(\mathrm{mmol} / \mathrm{l})$ & $3.3 \pm 0.1$ & $3.4 \pm 0.2$ & $3.6 \pm 0.2$ & 0.42 \\
Bilirubin $(\mu \mathrm{mol} / \mathrm{l})$ & $9.3 \pm 0.6$ & $8.8 \pm 1$ & $8.9 \pm 0.8$ & 0.86 \\
Amylase $(\mu \mathrm{kat} / \mathrm{l})$ & $0.4 \pm 0$ & $0.5 \pm 0$ & $0.4 \pm 0$ & 0.3 \\
Lipase $(\mu \mathrm{kat} / \mathrm{l})$ & $0.6 \pm 0$ & $0.7 \pm 0.1$ & $0.6 \pm 0$ & 0.54 \\
Arterial hypertension $(\%)$ & 83.3 & 56.25 & 46.4 & 0.006 \\
Hyperlipidaemia $(\%)$ & 61.1 & 37.5 & 35.7 & 0.09 \\
\hline
\end{tabular}

the respective inclusion criteria, they were asked to complete the Diabetes Bowel Symptom Questionnaire (DBSQ) and the Gastroparesis Cardinal Symptom Index (GCSI) questionnaire.

High-resolution oesophageal manometry The examination was performed in the morning (08:00 hours), following a fasting period of at least $12 \mathrm{~h}$. The test was performed using a solid-state catheter with 36 circumferential pressure sensors spaced at $1 \mathrm{~cm}$ intervals (Unisensor, Attikon, Switzerland) with the participants in the seated position. Details of the procedure are given in the ESM Methods.

$\left[{ }^{13} \mathrm{C}\right]$ Octanoic acid gastric emptying breath test The tests were performed at 08:00 hours after an overnight fast. A test meal was given comprising two muffins supplemented with $150 \mathrm{mg}$ sodium $\left[{ }^{13} \mathrm{C}\right]$ octanoate (Euriso-Top, Saint-Aubin, France) and consisting of $20.4 \mathrm{~g}$ fat, $12.4 \mathrm{~g}$ protein and $66.5 \mathrm{~g}$ carbohydrate. The total energy content was $2,098 \mathrm{~kJ}$. Venous blood samples were obtained twice at fasting and at 15 min intervals after meal ingestion for the measurement of plasma glucose. Breath specimens were sampled into gastight plastic bags for the determination of ${ }^{13} \mathrm{CO}_{2}$ content. The gastric retention-time profile as well as the gastric emptying $t_{1 / 2}$ and the time when $10 \%$ of the test meal was emptied from the stomach (lag time $\left[t_{\mathrm{LAG}}\right]$ ) were determined from the time profile of the excess ${ }^{13} \mathrm{C}$ concentration in the exhaled air. Details of the gastric emptying breath test are given in the ESM Methods. The morning medication of the study participants was taken after completion of the gastric emptying breath test.

\section{Laboratory determinations}

Plasma glucose concentrations were determined from venous blood samples using the glucose analyser SUPER GL easy (Dr Müller Gerätebau, Freital, Germany). A plasma biochemical profile was assessed in all subjects by standard in-hospital methods.

\section{DBSQ}

This questionnaire was introduced by Quan et al in 2003 and consists of various parts that contain questions about upper and lower gastrointestinal tract symptoms [28]. Details of the questionnaire are described in the ESM Methods.

\section{GCSI}

The GCSI questionnaire was developed to assess the severity of symptoms associated with gastroparesis [29]. The GCSI is based on a 2 week recall period and three subscales: postprandial fullness/early satiety, nausea/vomiting and bloating. The questionnaire contains nine questions that are scored from 0 to 5 points each. The minimum score is 0 points, while the maximum is 45 points. Higher scores indicate greater severity of symptoms. 
Statistical analyses

Data are presented as mean \pm SEM. Time course measurements were carried out by unpaired repeated-measures ANOVA, using Statistica version 5.0 (StatSoft Europe, Hamburg, Germany). Three different $p$ values were then calculated to determine: (1) overall differences between the different groups, independently of the respective time patterns; (2) differences over the time course, independently of the respective groups; and (3) differences between the groups over the time course. If a significant $(p<0.05)$ interaction between group and time was documented, values at single time points were compared by one-way ANOVA, followed by Duncan's post hoc test. All other variables were compared by one-way ANOVA, followed by Student's $t$ test. A $p$ value $<0.05$ was taken to indicate a significant difference. Correlation as well as contingency analyses were carried out using linear or non-linear regression functions and $\chi^{2}$ tests, respectively. GraphPad Prism 4 (La Jolla, CA, USA) software was used for these analyses.

\section{Results}

\section{Postprandial glucose concentrations}

As expected, fasting plasma glucose concentrations were higher in individuals with IFG/IGT and diabetes compared with those with NGT $(p<0.05$; Fig. 1). In individuals with IFG/IGT, postprandial glucose levels remained higher than in those with NGT over the entire $240 \mathrm{~min}$ after meal ingestion $(p<0.05)$. The postprandial course of glucose concentrations in diabetic individuals was much higher than in those with IFG/IGT or NGT $(p<0.001)$.

Consistent with previous studies, there was a significant linear correlation between the incremental glucose concentration $60 \mathrm{~min}$ after meal ingestion and the respective percentage of gastric retention at that time point $(r=-0.16, p=0.0002)$.

\section{Gastric emptying}

Eighty volunteers participated in the gastric emptying breath test (36 with diabetes, 16 with IFG/IGT, 28 with NGT). After $240 \mathrm{~min}, 19.4 \pm 3.4 \%, 29.9 \pm 3 \%$ and $15.9 \pm 2.4$ of the test meal was still retained in the stomach of participants with diabetes, IFG/IGT and NGT, respectively $(p=0.03)$. Also, the overall time course of gastric emptying was significantly delayed in IFG/IGT individuals, with significant differences vs NGT participants $60 \mathrm{~min}$ after meal ingestion (Fig. 1). The time course of gastric emptying was not different between individuals with diabetes and NGT.

There were no significant differences in gastric emptying $t_{1 / 2}(75.3 \pm 4.1,70.5 \pm 5.7$ and $77.1 \pm 11.1 \mathrm{~min}$, respectively; $p=$ $0.87)$ and $t_{\mathrm{LAG}}(27.6 \pm 1.6,30.8 \pm 4.1$ and $26.5 \pm 2.8 \mathrm{~min}$,
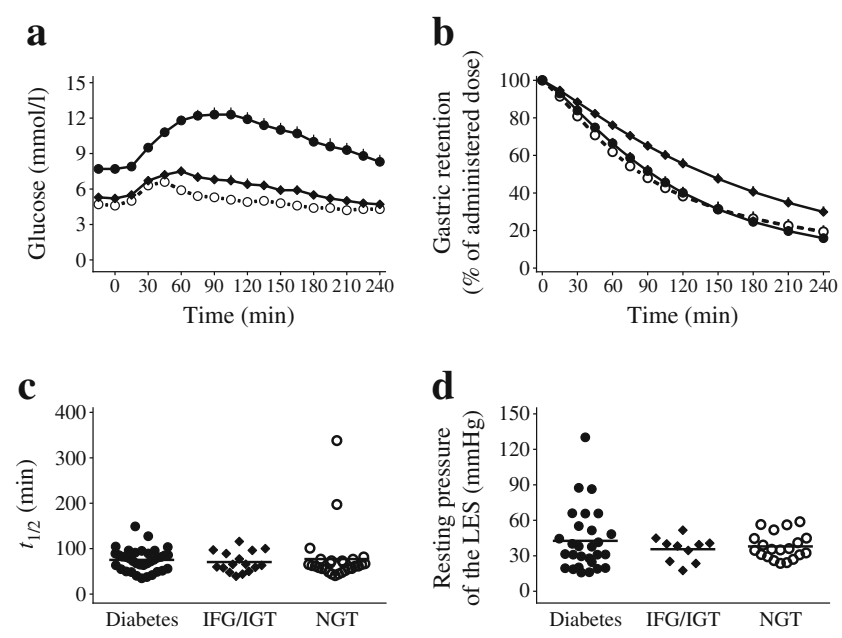

Fig. 1 Time courses of plasma glucose (a) and gastric retention (b) determined after ingestion of a mixed meal in 36 patients with type 2 diabetes, 16 individuals with IGT or IFG and 28 with NGT. Diabetes, IFG/IGT and NGT individuals' values are denoted by dots, rhombuses and circles, respectively. (c, d) Individual numbers for gastric emptying $t_{1 / 2}$ (c) and the resting pressure of the LES (d) are shown, determined in 28 patients with type 2 diabetes, ten individuals with IGT or IFG and 20 with NGT. Statistics in (a) and (b) were calculated using repeated-measures ANOVA and revealed the following $p$ values: differences over the time course, $p<0.0001$ in (a) and (b); differences between the groups, $p<0.0001$ in (a) and (b); and differences due to the interaction between group and time, $p<0.0001$ in (a) and (b). In (a), significant differences between patients with diabetes and IFG/IGT as well as between patients with diabetes and individuals with NGT were found at all time points, whereas significant differences between individuals with IFG/IGT and NGT were found from $t=60$ until $t=105 \mathrm{~min}$. In (b), significant differences between patients with diabetes and IFG/IGT were found between $t=30 \mathrm{~min}$ and $t=240 \mathrm{~min}$, and significant differences between individuals with IFG/IGT and NGT were found between $t=60 \mathrm{~min}$ and $t=240 \mathrm{~min}$. In (c) and (d), the $p$ values were 0.87 and 0.56 , respectively (one-way ANOVA)

respectively; $p=0.57$ ). To examine whether the duration of diabetes had an impact on gastric emptying, the group of patients with diabetes was divided into tertiles according to their diabetes duration. There was a significant difference in the time course of gastric emptying between the groups, with the patients with the longest diabetes duration exhibiting the fastest gastric emptying rate and those with the shortest duration showing the slowest gastric emptying rate $(p<0.0001$; Fig. 2). Gastric retention after $240 \mathrm{~min}$ was inversely correlated to diabetes duration $(r=-0.15, p=0.02)$.

To examine the impact of chronic hyperglycaemia on gastric emptying, the diabetic group was divided into tertiles according to $\mathrm{HbA}_{1 \mathrm{c}}$ levels. Gastric emptying was significantly faster in the tertile with the highest $\mathrm{HbA}_{1 \mathrm{c}}$ levels compared with the tertile with the lowest $\mathrm{HbA}_{1 \mathrm{c}}$ levels $(p<0.001)$.

High-resolution oesophageal manometry

Fifty-eight individuals underwent high-resolution oesophageal manometry ( 28 with diabetes, ten with IFG/IGT and 20 with 

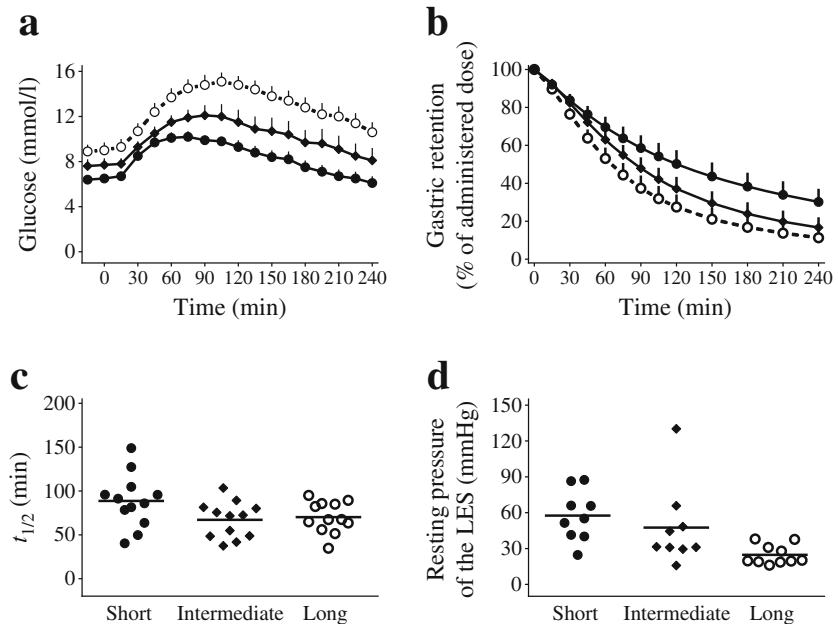

Fig. 2 Time courses of plasma glucose (a) and gastric retention (b), determined after ingestion of a mixed meal in patients with type 2 diabetes, grouped into tertiles according to diabetes duration. The values of the individuals with short, intermediate and long diabetes duration are denoted by dots, rhombuses and circles, respectively. (c, d) The individual numbers for gastric emptying $t_{1 / 2}$ (c), as well as the resting pressure of the LES (d) are shown. Statistics in (a) and (b) were calculated using repeated-measures ANOVA and revealed the following $p$ values: differences over the time course, $p=0.0006$ in (a) and $p=0.078$ in (b); differences between the groups, $p<0.0001$ in (a) and (b); and differences due to the interaction between group and time, $p<0.0001$ in (a) and (b). In (a), significant differences between patients with short and long diabetes duration were found at all time points, and significant differences between patients with intermediate and long diabetes duration were found from $t=$ 45 min until $t=240 \mathrm{~min}$. In (b), no significant differences were obtained at individual time points. In (c), the $p$ value was 0.07 ; in (d), the overall $p$ value was 0.015 (one-way ANOVA), with a significant difference between patients with short and long diabetes duration

NGT). There were no differences in oesophageal pressure, sphincter relaxation or contractile front velocity measurements between participants with diabetes, IFG/IGT or NGT (Table 2).

Table 2 Oesophageal manometry findings in participants with diabetes, IFG/IGT and NGT

Data are mean \pm SEM

$p$ values were calculated using one-way ANOVA
Using the normal ranges for upper oesophageal sphincter resting pressure, LES resting pressure, distal contractile front velocity, distal contractile integral, intrabolus pressure and integrated relaxation pressure, the number of participants with abnormal findings was $18(64.3 \%)$ in the diabetic group, five $(50 \%)$ in the IFG/IGT group and nine $(45 \%)$ in the NGT group $(p=0.39)$.

When the patients with diabetes were divided into tertiles according to their diabetes duration, the resting pressure of the LES was significantly higher in patients with shorter diabetes duration $(57.6 \pm 7,47.5 \pm 11.4$ and $24.8 \pm 2.6 \mathrm{mmHg}$ for patients with short, intermediate and long diabetes duration, respectively; $p=0.015$ ) (Fig. 2). This was confirmed by linear regression analysis, revealing a significant inverse relation between diabetes duration and LES resting pressure $(r=-0.31, p=0.002)$.

Abnormal LES resting pressure measurements were determined in six out of nine patients with short diabetes duration (67\%), two out of nine patients with intermediate diabetes duration $(22 \%)$ and zero out of ten patients with long diabetes duration $(0 \% ; p=0.005)$.

When the diabetic patients were categorised according to their $\mathrm{HbA}_{1 \mathrm{c}}$ level, no differences in any of the manometric variables became apparent (details not shown).

\section{DBSQ and GCSI}

The questionnaires were completed by 71 volunteers ( 35 with diabetes, 14 with IFG/IGT and 22 with NGT). Part A of the DBSQ (presence and severity of abdominal pain/discomfort within the last 3 months) revealed mean scores of $8.0 \pm 1.8$, $1.0 \pm 0$ and $4.7 \pm 1.7$ in participants with diabetes, IFG/IGT and NGT, respectively ( $p=0.04$ ). For part B1 (frequency of upper gastrointestinal symptoms within the last 3 months), the mean

\begin{tabular}{|c|c|c|c|c|c|}
\hline \multirow{12}{*}{ diabetes, IFG/IGT and NGT } & Upper sphincter — resting pressure $(\mathrm{mmHg})$ & $79.3 \pm 6.8$ & $99 \pm 12.8$ & $85 \pm 9.7$ & 0.4 \\
\hline & Upper sphincter-relaxation (\%) & $81.6 \pm 4.1$ & $87.8 \pm 1.8$ & $87.8 \pm 4.1$ & 0.46 \\
\hline & Lower sphincter - resting pressure $(\mathrm{mmHg})$ & $42.6 \pm 5$ & $35.6 \pm 3.3$ & $37.9 \pm 2.5$ & 0.56 \\
\hline & Lower sphincter-relaxation (\%) & $56.3 \pm 4.3$ & $63.2 \pm 7.1$ & $60.5 \pm 3$ & 0.59 \\
\hline & Proximal contractile front velocity $(\mathrm{cm} / \mathrm{s})$ & $5 \pm 0.8$ & $4.5 \pm 0.8$ & $4.7 \pm 0.6$ & 0.89 \\
\hline & $\begin{array}{l}\text { Proximal contractile integral } \\
\quad\left(\mathrm{mmHg} \mathrm{s} \mathrm{cm}^{-1}\right)\end{array}$ & $173.6 \pm 31.9$ & $243.4 \pm 82.7$ & $154.4 \pm 30.6$ & 0.43 \\
\hline & Proximal median amplitude $(\mathrm{mmHg})$ & $56.1 \pm 4.9$ & $64.2 \pm 7.9$ & $57.5 \pm 4.5$ & 0.65 \\
\hline & Distal contractile front velocity $(\mathrm{cm} / \mathrm{s})$ & $4.8 \pm 1$ & $3.9 \pm 0.4$ & $5.2 \pm 0.5$ & 0.72 \\
\hline & Distal contractile integral $\left(\mathrm{mmHg} \mathrm{s}^{-1} \mathrm{~cm}^{-1}\right)$ & $1,096.5 \pm 151.9$ & $1,531 \pm 347.8$ & $1,132.1 \pm 177.1$ & 0.37 \\
\hline & Distal median amplitude $(\mathrm{mmHg})$ & $92.9 \pm 6.7$ & $84.8 \pm 11.1$ & $79.8 \pm 6.9$ & 0.41 \\
\hline & Lowest pressure in transition zone $(\mathrm{mmHg})$ & $14.1 \pm 2.3$ & $18.6 \pm 2.7$ & $13.4 \pm 2.8$ & 0.5 \\
\hline & Intrabolus pressure $(\mathrm{mmHg})$ & $1 \pm 4.7$ & $4.4 \pm 2.9$ & $5 \pm 1.9$ & 0.73 \\
\hline Data are mean \pm SEM & Integrated relaxation pressure $(\mathrm{mmHg})$ & $25.9 \pm 4.2$ & $16.5 \pm 2$ & $20.3 \pm 1.7$ & 0.25 \\
\hline$p$ values were calculated using & Maximum amplitude (mmHg) & $183.3 \pm 13.2$ & $162.2 \pm 12.2$ & $172.7 \pm 15.5$ & 0.66 \\
\hline
\end{tabular}


scores were $13.4 \pm 0.5,13.0 \pm 1.0$ and $12.4 \pm 0.5$, respectively $(p=0.46)$. There were also no differences regarding the severity of symptoms in part B2 $(3.5 \pm 0.9,3.6 \pm 1.7$ and $2.9 \pm 0.9$, respectively; $p=0.89$ ).

The mean scores of the gastroparesis questionnaire were $3.2 \pm 0.8,3.4 \pm 1.5$ and $2.6 \pm 0.5$, respectively $(p=0.8$ ).

There were no differences in either part of the symptom scores of the DBSQ or the gastroparesis questionnaire between the different tertiles of diabetes duration or $\mathrm{HbA}_{1 \mathrm{c}}$ (details not shown).

Relationship between upper gastrointestinal functions and symptoms

Gastric emptying variables were unrelated to either part of the DBSQ or GCSI. By contrast, there was a significant association between part A of the DBSQ and LES resting pressure $(r=0.09, p=0.04)$, as well as between part A and integrated relaxation pressure $(r=0.15, p=0.005)$, indicating higher frequency and severity of abdominal pain/discomfort in individuals with a higher LES pressure and/or impaired LES relaxation during deglutition. There was also a significant association between distal contractile front velocity and part $\mathrm{B}$ of the DBSQ $(r=0.1, p=0.02$ and $r=0.26, p=0.0002$ for the first and second part of the DBSQ, respectively), indicating higher frequency and severity of upper gastrointestinal symptoms in individuals with faster contractions of the distal oesophagus. The latter was verified by the detection of a significant relation between distal contractile front velocity and GCSI $(r=0.18$, $p=0.002$ ). Gastrointestinal symptoms were unrelated to diabetes duration, $\mathrm{HbA}_{1 \mathrm{c}}$ level or vibration sense.

\section{Discussion}

The present study was designed to examine upper gastrointestinal motility and symptoms in individuals with diabetes, IFG/ IGT and NGT. Using a $\left[{ }^{13} \mathrm{C}\right]$ octanoate breath test and highresolution oesophageal manometry, we found no differences in gastric emptying or oesophageal motility between individuals with and without diabetes. In IFG/IGT individuals, however, gastric emptying was significantly delayed. Furthermore, in diabetic patients with long diabetes duration gastric emptying was faster, whereas the tone of the LES was highest in patients with short disease duration.

The lack of a general delay in gastric emptying in patients with diabetes was rather unexpected, as gastric emptying is often believed to be delayed in diabetic patients. However, previous studies have revealed normal, delayed or accelerated gastric emptying measurements in patients with diabetes [2, 17-23]. The discrepancies between the studies might reflect unequal patient characteristics. The present group of diabetic patients had relatively good metabolic control $\left(\mathrm{HbA}_{1 \mathrm{c}} 7 \%\right.$
[53 mmol/mol]) and an average diabetes duration of $\sim 10$ years. Importantly, they exhibited only minor signs of peripheral neuropathy. It is therefore likely that they were also largely unaffected by autonomic neuropathy. By contrast, most previous studies that have described gastric emptying abnormalities in patients with diabetes have included individuals in poorer glycaemic control $\left(\mathrm{HbA}_{1 \mathrm{c}} 8-11 \%\right.$ [64-97 $\left.\mathrm{mmol} / \mathrm{mol}\right]$ ) and with overt signs of neuropathy [2, 17-23]. In line with such reasoning, abnormal gastric emptying was found only in patients with long diabetes duration and a high $\mathrm{HbA}_{1 \mathrm{c}}$ level who also exhibited a significant reduction in vibration sense. Thus, only the results obtained in the subgroup of patients with long diabetes duration were comparable to the results of populations examined in previous studies, where the extent of late complications was rather extensive.

Arguably, abnormalities in gastric emptying in patients with diabetes might have been overlooked, because gastric emptying was determined using a breath test rather than by scintigraphy. However, the breath test applied has been shown to correlate well with gastric emptying scintigraphy and exhibits high sensitivity and specificity values [30]. Furthermore, it is theoretically possible that recruitment from a patient database and advertisements might have biased the selection of study participants, but the impact of this factor should be limited because of the similar recruitment strategy in all three groups.

Another surprising finding of this study was the delay in gastric emptying after $240 \mathrm{~min}$ in IFG/IGT individuals. It should be emphasised that, although statistically significant, these differences were modest in nature and no differences in gastric $t_{1 / 2}$ and $t_{\mathrm{LAG}}$ were observed. Given the absence of overt neuropathic complications in IFG/IGT individuals, this delay cannot readily be explained by autonomic neuropathy. More likely, the deceleration of gastric emptying in the IFG/IGT group might be secondary to hyperglycaemic excursions. Indeed, even though fasting glucose and $\mathrm{HbA}_{1 \mathrm{c}}$ levels were only modestly increased in the IFG/IGT group, there was a marked increase in postprandial hyperglycaemia in these individuals. Given the well-characterised negative impact of acute hyperglycaemia on the velocity of gastric emptying [14], it is likely that the rise in glucose levels secondarily caused a delay in gastric emptying. From a general physiological point of view, this glucose-induced retardation of gastric emptying might prevent excessive rises in postprandial glycaemia in IFG/IGT individuals.

The fact that gastric emptying was accelerated rather than delayed in patients with a higher $\mathrm{HbA}_{1 \mathrm{c}}$ value might argue against the impact of hyperglycaemia on gastric emptying. Unlike the prediabetic individuals, however, the patients with long-standing type 2 diabetes were exposed to chronically elevated hyperglycaemia rather than to brief hyperglycaemic excursions. Furthermore, autonomic neuropathy was more 
prevalent in these patients than in those at the earlier stages of the disease.

The low prevalence of delayed gastric emptying in patients with type 2 diabetes may nevertheless support the clinical use of glucose-lowering therapies that delay gastric emptying, such as GLP-1 analogues or amylin analogues, because presumably the efficacy of such treatments is diminished in patients with slow gastric emptying.

As a potential limitation of the present study, examination of gastro-oesophageal functions was restricted to the use of high-resolution manometry and did not include radiographic measurements of oesophageal transit times or $24 \mathrm{~h}$ oesophageal $\mathrm{pH}$ measurements. Previous studies using these methods, conventional oesophageal manometry or radionuclide emptying have revealed faster oesophageal transit times, abnormal oesophageal contractions and reduced pressure measurements of the LES in patients with diabetes [24-26]. These conditions have also been assumed to predispose to an increased risk of oesophageal reflux and even Barrett's oesophagus in diabetic patients [31,32]. However, overall very few studies have addressed oesophageal motility disorders in patients with diabetes [33, 34], and the majority have used conventional manometry catheters, which provide measurements at very few positions in the oesophagus. In the present study, high-resolution manometry was applied to obtain multiple pressure measurements throughout the oesophagus. In contrast to previous studies, no overall differences in oesophageal contractility, sphincter pressure or relaxation were found. In patients with shorter diabetes duration, however, the pressure of the LES was significantly increased compared with that in patients in the later stages of the disease. Overall, these findings suggest that oesophageal motility may be altered by the presence of hyperglycaemia [33, 34].

This study has also revealed a higher prevalence of abdominal pain/discomfort in patients with diabetes, in line with findings of previous studies $[35,36]$. Of note, the subjectively reported symptoms were largely unrelated to the velocity of gastric emptying. By contrast, oesophageal motility, especially the tone of the LES, was significantly related to the presence and severity of abdominal pain/discomfort. This indicates that the frequently reported abdominal discomfort in patients with diabetes is more likely to be secondary to abnormalities in oesophageal than in gastric motility. Therefore, oesophageal manometry should be considered for the diagnostic workup of such symptoms in patients with diabetes.

The GCSI used in this study was based on a 2 week recall period. Arguably, a daily diary might have provided a more reliable assessment of gastroparesis symptoms.

Overall, this study has revealed a much lower prevalence of gastric emptying and oesophageal manometry disorders in patients with type 2 diabetes than have previous studies [30]. Furthermore, no overt gastroparesis was found in this examination, and the degree of gastric emptying alterations, even in the cases with advanced diabetes, was mild. The relationship of both gastric and oesophageal disorders with diabetes duration or glucose control in this study suggests that improvements in diabetes care over recent decades have led to a reduction in manifest gastrointestinal disorders in patients with diabetes. This observation is in line with the reduction in mean $\mathrm{HbA}_{1 \mathrm{c}}$ levels over recent years, as well as the lower rates of myocardial infarction in diabetic patients [37, 38].

From a clinical point of view, both high-resolution manometry and the gastric emptying breath test can be useful assets for the diagnostic workup of patients with diabetes. It appears reasonable to determine gastric emptying in patients with otherwise unexplained postprandial glucose excursions to exclude accelerated gastric emptying. Furthermore, in patients with postprandial discomfort, oesophageal reflux and dysphagia, highresolution manometry might be a valuable diagnostic option following thorough endoscopic evaluation.

In conclusion, in the present group of patients with well-controlled type 2 diabetes, gastric emptying and oesophageal motility were not generally altered, suggesting that the extent of gastrointestinal disorders in patients with diabetes has been reduced over recent decades due to improved standards of care. In more advanced stages of the disease, however, gastric emptying was accelerated, whereas LES tone was increased in the early stages of the disease. The delay in gastric emptying in prediabetic individuals might be secondary to the acute rises in postprandial glucose concentrations. The observed association between upper gastrointestinal symptoms and oesophageal motility suggests that oesophageal manometry should be considered for the diagnostic workup of patients with diabetes and gastrointestinal symptoms.

Acknowledgements The technical assistance of B. Baller and M. Schweinsberg (both St Josef Hospital, Ruhr University Bochum, Bochum, Germany) is greatly acknowledged.

Funding This study was supported by grants from the Ruhr University Bochum (FoRUM).

Duality of interest JJM has received consulting and speaker honoraria from Astra Zeneca, BMS, Eli Lilly, MSD, Novo Nordisk and Sanofi. He has received research support from Eli Lilly, Boehringer-Ingelheim, MSD, Novo Nordisk, Novartis and Sanofi. GCB, BAM, NS, TGKB, FS, SH and J-MO have no conflicts of interest.

Contribution statement GCB performed the experiments, analysed the data and contributed to the manuscript preparation. BAM and NS helped to design the study, performed the experiments and edited the manuscript. TGKB and J-MO helped to perform the experiments, discussed the data and edited the manuscript. SH and FS analysed the data, discussed the results and edited the manuscript. JJM designed the study, helped to perform the experiments, analysed the data and prepared the manuscript. All authors have approved the final version of the manuscript. JJM is the guarantor of this work. 


\section{References}

1. Sellin JH, Chang EB (2008) Therapy insight: gastrointestinal complications of diabetes - pathophysiology and management. Nat Clin Pract Gastroenterol Hepatol 5:162-171

2. Horowitz M, O'Donovan D, Jones KL, Feinle C, Rayner CK, Samsom M (2002) Gastric emptying in diabetes: clinical significance and treatment. Diabet Med 19:177-194

3. Horowitz M, Fraser R (1994) Disordered gastric motor function in diabetes mellitus. Diabetologia 37:543-551

4. Horowitz M, Edelbroek MA, Wishart JM, Straathof JW (1993) Relationship between oral glucose tolerance and gastric emptying in normal healthy subjects. Diabetologia 36:857-862

5. Moyses C, Young A, Kolterman O (1996) Modulation of gastric emptying as a therapeutic approach to glycaemic control. Diabet Med J Br Diabet Assoc 13(Suppl 5):S34-S38

6. Kolterman OG, Gottlieb A, Moyses C, Colburn W (1995) Reduction of postprandial hyperglycemia in subjects with IDDM by intravenous infusion of AC137, a human amylin analogue. Diabetes Care 18: 1179-1182

7. Meier JJ, Gallwitz B, Salmen S et al (2003) Normalization of glucose concentrations and deceleration of gastric emptying after solid meals during intravenous glucagon-like peptide 1 in patients with type 2 diabetes. J Clin Endocrinol Metab 88:2719-2725

8. Meier JJ, Kemmeries G, Holst JJ, Nauck MA (2005) Erythromycin antagonizes the deceleration of gastric emptying by glucagon-like peptide 1 and unmasks its insulinotropic effect in healthy subjects. Diabetes 54:2212-2218

9. Gonlachanvit S, Hsu CW, Boden GH et al (2003) Effect of altering gastric emptying on postprandial plasma glucose concentrations following a physiologic meal in type-II diabetic patients. Dig Dis Sci 48: 488-497

10. Meier JJ, Gallwitz B, Kask B et al (2004) Stimulation of insulin secretion by intravenous bolus injection and continuous infusion of gastric inhibitory polypeptide in patients with type 2 diabetes and healthy control subjects. Diabetes 53(Suppl 3):S220-S224

11. Meier JJ, Gallwitz B, Nauck MA (2003) Glucagon-like peptide 1 and gastric inhibitory polypeptide: potential applications in type 2 diabetes mellitus. BioDrugs 17:93-102

12. Creutzfeldt W (1979) The incretin concept today. Diabetologia 16: $75-85$

13. Nauck MA, Baller B, Meier JJ (2004) Gastric inhibitory polypeptide and glucagon-like peptide-1 in the pathogenesis of type 2 diabetes. Diabetes 53(Suppl 3):S190-S196

14. Schvarcz E, Palmer M, Aman J, Horowitz M, Stridsberg M, Berne C (1997) Physiological hyperglycemia slows gastric emptying in normal subjects and patients with insulin-dependent diabetes mellitus. Gastroenterology 113:60-66

15. Vollmer K, Gardiwal H, Menge BA et al (2009) Hyperglycemia acutely lowers the postprandial excursions of glucagon-like peptide-1 and gastric inhibitory polypeptide in humans. J Clin Endocrinol Metab 94:1379-1385

16. Plummer MP, Jones KL, Annink CE et al (2014) Glucagon-like peptide 1 attenuates the acceleration of gastric emptying induced by hypoglycemia in healthy subjects. Diabetes Care 37:1509-1515

17. Schwartz JG, Green GM, Guan D, McMahan CA, Phillips WT (1996) Rapid gastric emptying of a solid pancake meal in type II diabetic patients. Diabetes Care 19:468-471

18. Ziegler D, Schadewaldt P, Pour Mirza A et al (1996) $\left[{ }^{13} \mathrm{C}\right]$ Octanoic acid breath test for non-invasive assessment of gastric emptying in diabetic patients: validation and relationship to gastric symptoms and cardiovascular autonomic function. Diabetologia 39:823-830

19. Lehmann R, Borovicka J, Kunz P et al (1996) Evaluation of delayed gastric emptying in diabetic patients with autonomic neuropathy by a new magnetic resonance imaging technique and radio-opaque markers. Diabetes Care 19:1075-1082

20. Bertin E, Schneider N, Abdelli N et al (2001) Gastric emptying is accelerated in obese type 2 diabetic patients without autonomic neuropathy. Diabetes Metab 27:357-364

21. Kong MF, Macdonald IA, Tattersall RB (1996) Gastric emptying in diabetes. Diabet Med J Br Diabet Assoc 13:112-119

22. Faraj J, Melander O, Sundkvist G et al (2007) Oesophageal dysmotility, delayed gastric emptying and gastrointestinal symptoms in patients with diabetes mellitus. Diabet Med J Br Diabet Assoc 24: $1235-1239$

23. Camilleri M (2007) Clinical practice. Diabetic gastroparesis. N Engl J Med 356:820-829

24. Annese V, Bassotti G, Caruso N et al (1999) Gastrointestinal motor dysfunction, symptoms, and neuropathy in noninsulin-dependent (type 2) diabetes mellitus. J Clin Gastroenterol 29:171-177

25. Jorge JX, Panao EA, Simoes MA et al (2012) Esophageal body motility in people with diabetes: comparison with non-diabetic healthy individuals. Diabetes Res Clin Pract 97:77-81

26. Ohlsson B, Melander O, Thorsson O, Olsson R, Ekberg O, Sundkvist G (2006) Oesophageal dysmotility, delayed gastric emptying and autonomic neuropathy correlate to disturbed glucose homeostasis. Diabetologia 49:2010-2014

27. Genuth S, Alberti KGMM, Bennett P et al (2003) Follow-up report on the diagnosis of diabetes mellitus. Diabetes Care 26:3160-3167

28. Quan C, Talley NJ, Cross S et al (2003) Development and validation of the Diabetes Bowel Symptom Questionnaire. Aliment Pharmacol Ther 17:1179-1187

29. Revicki DA, Rentz AM, Dubois D et al (2004) Gastroparesis Cardinal Symptom Index (GCSI): development and validation of a patient reported assessment of severity of gastroparesis symptoms. Qual Life Res Int J Qual Life Asp Treat Care Rehab 13:833-844

30. Chang J, Rayner CK, Jones KL, Horowitz M (2011) Diabetic gastroparesis - backwards and forwards. J Gastroenterol Hepatol 26(Suppl 1):46-57

31. Iyer PG, Borah BJ, Heien HC, Das A, Cooper GS, Chak A (2013) Association of Barrett's esophagus with type II diabetes mellitus: results from a large population-based case-control study. Clin Gastroenterol Hepatol Off Clin Pract J Am Gastroenterol Assoc 11: $1108-1114$

32. Murray FE, Lombard MG, Ashe J et al (1987) Esophageal function in diabetes mellitus with special reference to acid studies and relationship to peripheral neuropathy. Am J Gastroenterol 82:840-843

33. Zhang Q, Horowitz M, Rigda R, Rayner C, Worynski A, Holloway RH (2004) Effect of hyperglycemia on triggering of transient lower esophageal sphincter relaxations. Am J Physiol Gastrointest Liver Physiol 286:G797-G803

34. Boeckxstaens GE, Horowitz M, Bermingham H, Holloway RH (1997) Physiological variations in blood glucose concentration affect oesophageal motility and sensation in normal subjects. Neurogastroenterol Motil 9:239-246

35. Quan C, Talley NJ, Jones MP, Howell S, Horowitz M (2008) Gastrointestinal symptoms and glycemic control in diabetes mellitus: a longitudinal population study. Eur J Gastroenterol Hepatol 20:888897

36. Quan C, Talley NJ, Jones MP, Spies J, Horowitz M (2008) Gain and loss of gastrointestinal symptoms in diabetes mellitus: associations with psychiatric disease, glycemic control, and autonomic neuropathy over 2 years of follow-up. Am J Gastroenterol 103:2023-2030

37. Ali MK, Bullard KM, Saaddine JB, Cowie CC, Imperatore G, Gregg EW (2013) Achievement of goals in U.S. diabetes care, 1999-2010. N Engl J Med 368:1613-1624

38. Saaddine JB, Cadwell B, Gregg EW et al (2006) Improvements in diabetes processes of care and intermediate outcomes: United States, 1988-2002. Ann Intern Med 144:465-474 